\title{
A Survey of Academic Intensivists' Use of Neuromuscular Blockade in Subjects With ARDS
}

\author{
Neal N Dodia, Mary E Richert, Andrew R Deitchman, Charlene C Quinn, Ellen T Marciniak, \\ Clayton H Brown, Michael L Terrin, Diana E Amariei, Carl B Shanholtz, and Jeffrey D Hasday
}

\begin{abstract}
BACKGROUND: Our Cooling to Help Injured Lungs (CHILL) trial of therapeutic hypothermia in ARDS includes neuromuscular blockade (NMB) as an inclusion criterion to avoid shivering. NMB has been used to facilitate mechanical ventilation in ARDS and was shown to reduce mortality in the ACURASYS trial. To assess the feasibility of a multi-center CHILL trial, we conducted a survey of academic intensivists about their NMB use in patients with ARDS. METHODS: We distributed via email a 16-question survey about NMB use in patients with ARDS including frequency, indications, and dosing strategy. RESULTS: $212(24.3 \%)$ of 871 respondents completed the survey: 94.7\% were board-certified in internal medicine, $88 \%$ in pulmonary and critical care; $90.3 \%$ practiced in academic medical centers, with $87 \%$ working in medical ICUs; $96.6 \%$ of respondents who treat ARDS use NMB, and $39.7 \%$ use NMB in $\geq 50 \%$ of these patients. Of 4 listed indications for initiating NMB in ARDS, allowing adherence with lung-protective ventilator strategies and patient-ventilator synchrony were cited as the most important reasons, followed by the results of the ACURASYS trial and facilitating prone positioning. CONCLUSIONS: We conclude that NMB is frequently used by academic intensivists to facilitate mechanical ventilation in patients with moderate to severe ARDS. Key words: neuromuscular blockade; acute respiratory distress syndrome; survey; intensivist; ACURASYS trial; lung-protective ventilation; mechanical ventilation. [Respir Care 2020;65(3):362-368. (C) 2020 Daedalus Enterprises]
\end{abstract}

\section{Introduction}

ARDS remains an important health problem with substantial mortality and morbidity. ${ }^{1-9}$ Despite advances in understanding ARDS pathogenesis, ${ }^{10,11}$ only 3 interventions have been shown to reduce mortality in phase 3 randomized controlled trials: low tidal-volume ventilation, ${ }^{12}$ neuromuscular blockade (NMB), ${ }^{13}$ and prone posi-

Drs Dodia, Richert, Deitchman, Marciniak, Amariei, Shanholtz, and Hasday are affiliated with the Division of Pulmonary and Critical Care Medicine, Department of Medicine, University of Maryland School of Medicine, Baltimore, Maryland. Drs Quinn, Brown, and Terrin are affiliated with the Department of Epidemiology and Public Health, University of Maryland School of Medicine, Baltimore, Maryland. Dr Hasday is also affiliated with the Baltimore Veterans Administration Medical Center, Baltimore, Maryland.

The authors have disclosed no conflicts of interest.

Supplementary material related to this paper is available at http:// www.rcjournal.com. tioning. ${ }^{14}$ Currently, mortality in moderate to severe ARDS remains $>40 \% . .^{15,16}$ Based on studies in cell cultures, animal models, and small clinical studies, we developed the hypothesis that therapeutic hypothermia during the early stage of ARDS would mitigate lung injury and improve clinical outcome. However, cooling in critically ill patients is complicated by shivering and its adverse metabolic consequences, ${ }^{17}$ which invariably requires pharmacologic suppression, including NMB. Thus, a randomized controlled trial of therapeutic hypothermia versus usual temperature management in subjects with ARDS would be confounded by an unavoidable imbalance in rates of shivering and anti-shivering drug use between the therapeutic hypothermia and control arms. We sought to avoid this pitfall by

\footnotetext{
Correspondence: Jeffrey D Hasday MD, Department of Medicine, University of Maryland School of Medicine, 110 S. Paca St, Room 2N149, Baltimore, MD 21201. E-mail: jhasday@medicine.umaryland.edu.
}

DOI: $10.4187 /$ respcare. 07026 
exploiting the increased clinical use of NMB in patients with moderate to severe ARDS and testing the potential benefit of therapeutic hypothermia in patients with ARDS who were already receiving NMB. Our Cooling to Help Injured Lungs (CHILL) pilot study supported the feasibility of this strategy. ${ }^{18}$

However, successful completion of such a clinical trial depends on the continued practice of using NMB to manage patients with ARDS. Although NMB has been used as ancillary therapy to facilitate mechanical ventilation for the past 4 decades, ${ }^{19}$ there is little data available about the current patterns of NMB administration in patients with ARDS; specifically, the frequency of NMB use in patients with ARDS, the duration of administration, and the clinical reasoning for its use. The ACURASYS trial, ${ }^{13}$ published in 2010, was the first (and is currently the only) phase 3 randomized controlled trial to show a survival benefit of early NMB administration in moderate to severe ARDS. In this trial, subjects who were randomized to $48 \mathrm{~h}$ of NMB with a fixed dose of cisatracurium had a hazard ratio for death of $0.68(P<.04)$ compared to the control arm after adjusting for baseline $\mathrm{P}_{\mathrm{aO}_{2}} / \mathrm{F}_{\mathrm{IO}_{2}}$ and no increase in risk of serious adverse events, including myopathy. However, NMB has been used for the past 3 decades as adjuvant therapy to manage respiratory failure, ${ }^{20}$ including in 25-55\% of subjects with ARDS in clinical trials published before 2010.21-24 Several limitations of the ACURASYS trial have been identified, including its failure to find a difference in crude mortality rate, the use of low levels of PEEP, and the fact that ACURASYS ${ }^{13}$ and the 2 smaller trials on which it was based were all conducted by the same research group. ${ }^{25}$ To resolve these issues, the National Heart, Lung, and Blood Institute's PETAL network conducted the ROSE trial, ${ }^{26}$ which sought to confirm the results of ACURASYS. ${ }^{13}$ In light of our ongoing studies of therapeutic hypothermia in ARDS, we sought to understand the current patterns of NMB use in patients with ARDS and to predict the potential impact of the ROSE trial $^{26}$ on the feasibility of a larger, multi-center, randomized clinical trial of therapeutic hypothermia in subjects with ARDS receiving NMB.

We performed a cross-sectional, web-based survey of academic intensivists about their patterns of NMB use in patients with ARDS, including frequency of use, duration of administration, dosing and monitoring, and importantly the clinical reasoning behind their decisions to use NMB in ARDS patients.

\section{Methods}

\section{Survey Design}

The survey was developed based on the CHERRIES checklist by a survey writing team of 2 pulmonary and

\section{QUICK LOOK}

\section{Current knowledge}

Available observational studies and small surveys suggest that neuromuscular blockade (NMB) is commonly used to treat patients with ARDS. The ACURASYS trial demonstrated improved adjusted 90-day survival in patients with ARDS who received a fixed NMB, but NMB has been used prior to publication of the ACURASYS results to facilitate mechanical ventilation.

\section{What this paper contributes to our knowledge}

Our web-based survey, completed by participants at 48 academic institutions, showed that a very high proportion of academic intensivists who treat patients with moderate to severe ARDS frequently use NMB in their management. The most important consideration in initiating NMB in patients with ARDS is facilitating lungprotective mechanical ventilation and maintaining patient-ventilatory synchrony. The vast majority of intensivists who use NMB in patients with ARDS adjust the dose based on patient response to nerve stimulation or patient-ventilator synchrony, rather than administering a fixed dose.

critical care medicine faculty members (CBS, JDH), 3 pulmonary and critical care medicine fellows (NND, ARD, DEA), and an internal medicine resident (MR), all from the University of Maryland. ${ }^{27}$ The aims of the survey were to determine the frequency of NMB use in patients with ARDS, the duration of NMB administration in such patients, the method for dosing and monitoring NMB drugs, and the clinical reasoning behind the decision to use NMB in patients with moderate to severe ARDS. Based on the inclusion criteria used in the ACURASYS ${ }^{13}$ and ROSE trials, ${ }^{26}$ moderate to severe ARDS in the survey was defined as $\mathrm{P}_{\mathrm{aO}_{2}} / \mathrm{F}_{\mathrm{IO}_{2}}<150 \mathrm{~mm} \mathrm{Hg}$, along with other Berlin criteria. The survey was approved by the University of Maryland School of Medicine Institutional Review Board.

The survey writing team generated an initial 16-question survey that included 6 demographic questions, 3 questions about whether the respondent managed patients with ARDS and whether they used NMB in their management of such patients, and 7 questions describing their pattern of NMB use in patients with ARDS (see the supplementary materials at http://www.rcjournal.com). All questions included "Refuse to answer" and "Don't know" as options. Only a single answer was permitted per question. A write-in option was allowed for the 2 questions describing the respondents' training. The respondents were not required to fill in an answer to proceed, with the exception that access to the final 7 questions was conditional on answering "Yes" 
to questions 8 and 9 about using NMB in patients with ARDS. The final survey questionnaire incorporated changes suggested by a statistician with expertise in survey questionnaire development (CCQ) and by 10 intensivists at the University of Maryland who trialed the survey. In 4 successive questions using the same general wording, the respondents were asked about the degree of importance they placed on each of 4 reasons to use NMB in patients with moderate to severe ARDS: (1) promoting synchrony with the mechanical ventilator, (2) allowing compliance with ARDSNet mechanical ventilation guidelines, (3) facilitating prone positioning, and (4) the ACURASYS trial. ${ }^{13}$ The survey was distributed via email with the Qualtrics Survey platform (Qualtrics International, Provo, Utah).

\section{Survey Subjects}

We identified academic critical care practices within the United States that had a Fellowship in Pulmonary and Critical Care Medicine accredited by the Accreditation Council for Graduate Medical Education to participate in a cross-sectional survey regarding the use of NMB in moderate to severe ARDS. Institutions participating in the PETAL network were excluded. We identified critical care practitioners either from the program website or by contacting the program administrative office. The survey was sent to 870 intensivists at 53 programs within the United States, 51 of which were university-based and 2 of which were large, community-based health systems.

\section{Survey Administration}

The survey was deployed on September 12, 2018, followed by 3 reminder emails automatically sent by the Qualtrics Survey platform at 1-week intervals for nonresponders. Participation in the survey was voluntary, and no incentives were offered. All data were collected with the Qualtrics platform and downloaded as a spreadsheet. Emails contained a link to the online survey, and each recipient received a unique identifier to prevent multiple submissions.

\section{Statistical Methods}

The sum of total answers for subsets of patients may not equal the number of answers for all patients if the question used to describe subsets includes blank answers. To determine the rank order of importance placed on each of the 4 potential reasons to initiate NMB in ARDS patients, we calculated a numerical score for each of the 4 indications based on assigned numerical values for each answer: 0 for not at all important, refused to answer, or don't know; 1 for slightly important; 2 for moderately important; 3 for very important; and 4 for extremely important. Differences in patterns of answers between questions and between subgroups of respondents were analyzed by Chi-square, with $P<.05$ considered significant. Fields that were left blank were not included in the analysis.

\section{Results}

Of the 870 intensivists who were emailed an invitation to complete the survey, 33 invitations bounced back (i.e., undeliverable), 231 individuals (27.2\% of delivered emails) started the survey, and 212 individuals (25.3\%) completed the survey, representing 48 of the 53 institutions included. Of the 212 respondents who completed the survey, 108 responded to the initial email, 65 responded after the first reminder, 34 after the second reminder, and 5 after the third reminder. A total of 199 of $210(94.8 \%)$ respondents were board-certified in internal medicine, 183 of $208(88 \%)$ practiced pulmonary and critical care, 5 of $183(2.4 \%)$ practiced critical care combined with another subspecialty, and 20 of 183 (9.6\%) practiced critical care alone (Table 1). A total of 187 of 207 (90.3\%) respondents practiced predominantly in an academic medical center, $13(6.3 \%)$ practiced in a Veterans Affairs medical center, $5(2.4 \%)$ practiced in a large community hospital, and $2(1 \%)$ practiced in a small community hospital. A total of 181 of 208 (87\%) respondents practiced predominantly in a medical ICU, and 27 (13\%) practiced in a medicalsurgical ICU. Years in practice were evenly distributed with 66 (31.8\%) having $0-5$ y intensive care practice experience, 56 (26.9\%) having 6-10 y 41 (19.7\%) having $11-19$ y and 45 (21.6\%) having $\geq 20$ y 136 of $208(65.4 \%)$ of the respondents worked at least 9 weeks per year in an ICU. Of the 209 respondents who answered, 206 (98.6\%) confirmed that they care for patients with moderate to severe ARDS, and 127 of $190(66.8 \%)$ care for $\geq 11$ such patients per year. Of the 206 intensivists who care for patients with moderate to severe ARDS, 198 of 205 answering the question $(96.1 \%)$ use NMB agents in these patients, and $75(39.7 \%)$ use NMB in $\geq 50 \%$ of these patients (Table 2). Of the 198 respondents who use NMB in patients with ARDS, $177(89.4 \%)$ answered all questions in the survey. Four of the respondents who answered "Yes" to questions about caring for patients with moderate to severe ARDS and using NMB failed to answer any subsequent survey questions and were not included in the analysis.

Of the respondents who use NMB to manage patients with ARDS, 143 of $191(74.9 \%)$ usually administer NMB agents for $25-48 \mathrm{~h}$ and 27 (14.1\%) respondents for $\geq 48 \mathrm{~h}$. The rank order of reported importance of the 4 potential indications for using NMB in ARDS patients was (1) allowing compliance with ARDSNet mechanical ventilation guidelines (mean numerical score 3.43); (2) promoting patient-ventilator synchrony (mean numerical score 2.99); 
Table 1. Respondent Training and Practice

\begin{tabular}{lc}
\hline \hline & Number of \\
& Responses $(\%)$ \\
\hline Primary specialty & $210(100)$ \\
Internal medicine & $199(94.7)$ \\
Neurology & $1(0.5)$ \\
Emergency medicine & $2(1.0)$ \\
Medicine/Pediatrics & $1(0.5)$ \\
Medicine/Emergency medicine & $2(1.0)$ \\
Other & $5(2.3)$ \\
Type of critical care practice & $208(100)$ \\
Pulmonary and critical care & $183(88)$ \\
Critical care with another subspecialty & $5(2.4)$ \\
Critical care alone & $20(9.6)$ \\
Years practicing critical care & $208(100)$ \\
$0-5$ & $66(31.8)$ \\
$6-10$ & $56(26.9)$ \\
$11-19$ & $41(19.7)$ \\
$\geq 20$ & $45(21.6)$ \\
Type of primary practice site & $207(100)$ \\
Academic medical center & $187(90.3)$ \\
Large community hospital $(\geq 250$ beds) & $5(2.4)$ \\
Small community hospital & $2(1.0)$ \\
Veterans Affairs medical center & $13(6.3)$ \\
Type of primary ICU site & $208(100)$ \\
Medical ICU & $181(87)$ \\
Medical/Surgical ICU & $27(13)$ \\
Weeks per year in ICU & $208(100)$ \\
$0-4$ & $19(9.1)$ \\
$5-8$ & $53(25.5)$ \\
13-24 & $88(42.3)$ \\
$\geq 25$ & $42(20.2)$ \\
\hline & $6(2.9)$ \\
\hline
\end{tabular}

(3) the ACURASYS trial results (mean numerical score 2.69); (4) facilitating prone positioning (mean numerical score 2.41) $(P<.001)$ (Table 3$)$. There was no difference in the distribution of answers about the reasons for initiating NMB in patients with ARDS between subgroups of respondents based on years of critical care experience, numbers of patients with ARDS cared for per year, or type of practice site, and no regional differences in the frequency or duration of NMB use (see the supplementary materials at http://www.rcjournal.com). In the absence of information about the individuals who did not respond to this survey, we estimated the nonresponder bias by utilizing the late responders as a surrogate for nonresponders as suggested by Lin and Schaeffer. ${ }^{28}$ Comparing the survey answers of the early responders, defined as those who completed the survey within one week of the initial email, and late responders showed no difference between the groups in the level and type of training, ARDS practice patterns, NMB utilization, and distribution of answers regarding reasons for using NMB in patients with
Table 2. ARDS Practice and NMB Utilization

\begin{tabular}{lc}
\hline \hline & Number of \\
& Responses $(\%)$ \\
\hline Manage patients with ARDS & $209(100)$ \\
Yes & $206(98.6)$ \\
No & $3(1.4)$ \\
Use NMB for ARDS & $205(100)$ \\
Yes & $198(96.6)$ \\
No & $7(3.4)$ \\
ARDS patients per year, $n$ & $190(100)$ \\
$0-5$ & $9(4.7)$ \\
$6-10$ & $54(28.4)$ \\
$11-14$ & $60(31.6)$ \\
$\geq 15$ & $67(35.3)$ \\
$\%$ ARDS patients treated with NMB & $189(100)$ \\
$0-15$ & $20(10.6)$ \\
$16-25$ & $32(16.9)$ \\
$26-35$ & $30(15.9)$ \\
$36-49$ & $32(16.9)$ \\
$\geq 50$ & $75(39.7)$ \\
Usual duration of NMB infusion in ARDS, h & $191(100)$ \\
$0-12$ & $2(1.0)$ \\
$13-24$ & $19(10)$ \\
$25-48$ & $143(74.9)$ \\
$\geq 48$ & $27(14.1)$ \\
Usual method of NMB dosing & $194(100)$ \\
Fixed dose & $10(5.2)$ \\
Fixed dose base on body weight & $9(4.7)$ \\
Titrate to mechanical ventilation goals & $41(21.1)$ \\
Titrate based on train-of-four monitoring & $132(68)$ \\
Refused to answer & $2(1.0)$ \\
& \\
ARDS was defined as PaO $_{2} /$ F $_{\text {IO }}<$ & $<150$ mm Hg, along with other Berlin criteria. \\
NMB $=$ neuromuscular blockade & \\
\hline & \\
\hline
\end{tabular}

ARDS (see the supplementary materials at http://www. rcjournal.com).

Of the 198 respondents who use NMB in their management of patients with ARDS, $132(68 \%)$ titrate NMB agents using train-of-four monitoring, $41(21.1 \%)$ titrate to clinical effect, and 19 (9.9\%) use a fixed dose.

\section{Discussion}

The goal of this study was to understand current patterns of NMB utilization by academic intensivists in patients with ARDS $\left(\mathrm{P}_{\mathrm{aO}_{2}} / \mathrm{F}_{\mathrm{IO}_{2}}<150 \mathrm{~mm} \mathrm{Hg}\right)$ with respect to frequency of use, duration of administration, reasons for initiating, and method of dosing. The data will be used to assess study feasibility and help design a multi-center randomized controlled trial of therapeutic hypothermia in subjects with moderate to severe ARDS who are being managed with NMB. Because we plan to conduct the multicenter trial of therapeutic hypothermia in ARDS in aca- 
Table 3. Relative Importance of Reasons to Initiate NMB in Patients With ARDS

\begin{tabular}{|c|c|c|c|c|}
\hline \multirow{2}{*}{ Degree of Importance } & \multicolumn{4}{|c|}{ Number (\%) of Each Answer About Reasons to Initiate NMB } \\
\hline & Patient-Ventilator Synchrony & Meet ARDSNet Guidelines & Facilitate Proning & Results of ACURASYS \\
\hline Extremely & $63(32.5)$ & 115 (59.3) & $43(22.2)$ & 40 (20.6) \\
\hline Very & $83(42.8)$ & $54(27.8)$ & $54(27.8)$ & $83(42.8)$ \\
\hline Moderately & $34(17.5)$ & $19(9.8)$ & $51(26.3)$ & $41(21.1)$ \\
\hline Slightly & $12(6.2)$ & $5(2.6)$ & $32(16.5)$ & $17(8.8)$ \\
\hline Not at all & $1(0.5)$ & $1(0.5)$ & $12(6.2)$ & $1(0.5)$ \\
\hline Left blank & $1(0.5)$ & $0(0)$ & $2(1.0)$ & $12(6.2)$ \\
\hline Total & 194 & 194 & 194 & 194 \\
\hline Mean score* & 2.99 & 3.43 & 2.41 & $2.69^{\dagger}$ \\
\hline \multicolumn{5}{|c|}{$\begin{array}{l}\text { ARDS was defined as } \mathrm{P}_{\mathrm{aO}} / \mathrm{F}_{\mathrm{IO}}<150 \mathrm{~mm} \mathrm{Hg} \text {, along with other Berlin criteria. } \\
\text { * Based on value of } 4 \text { for extremely, } 3 \text { for very, } 2 \text { for moderately, } 1 \text { for slightly, and } 0 \text { for not at all or left blank. } \\
\dagger \text { Pattern of answers is different among the } 4 \text { questions. } \\
P<.001 \text {. } \\
\text { NMB }=\text { neuromuscular blockade }\end{array}$} \\
\hline
\end{tabular}

demic medical centers, we focused the survey of NMB use in patients with ARDS in this setting. While $90 \%$ of respondents practiced predominantly in academic medical centers, the answers from the $10 \%$ of respondents who practice in Veterans Administration medical centers or community hospitals were similar to those who practice in academic centers. The high proportion of internal medicine and pulmonary critical care board-certified physicians among the respondents reflected our strategy of targeting critical care practices associated with accredited pulmonary/critical care programs, but we note that the answers from the $13 \%$ of respondents who predominantly practice in medical/surgical ICUs were similar to those who predominantly practice in medical ICUs.

The results of the survey provide clear answers about how NMB agents are used in patients with ARDS. A very high proportion $(96.6 \%)$ of intensivists who treat patients with moderate to severe ARDS use NMB, and almost $40 \%$ of these respondents use NMB in more than half their patients with moderate to severe ARDS. These results are in line with other recent surveys. The LUNG SAFE study, a prospective study of 459 ICUs in 50 countries conducted in the winter of 2014 , found that $37.8 \%$ of subjects with severe ARDS $\left(\mathrm{P}_{\mathrm{aO}_{2}} / \mathrm{F}_{\mathrm{IO}_{2}}<100 \mathrm{~mm} \mathrm{Hg}\right)$ received NMB as part of their management. ${ }^{29}$ In an observational study of ARDS management in 23 Canadian and one Saudi Arabian hospital, NMB was used in $42 \%$ of 664 subjects with ARDS defined as $\mathrm{P}_{\mathrm{aO}_{2}} / \mathrm{F}_{\mathrm{IO}_{2}}<200 \mathrm{~mm} \mathrm{Hg}$ and in $63 \%$ of subjects with ARDS defined as $\mathrm{P}_{\mathrm{aO}_{2}} / \mathrm{F}_{\mathrm{IO}_{2}}<100 \mathrm{~mm} \mathrm{Hg} .{ }^{30}$ A survey of ICU physicians, fellows, nurse practitioners, physician assistants, respiratory therapists, and pharmacists in 5 academic medical centers about their perceptions of NMB safety and efficacy in ARDS revealed that $36 \%$ of respondents would use continuously infused NMB in patients with ARDS $\left(\mathrm{P}_{\mathrm{aO}_{2}} / \mathrm{F}_{\mathrm{IO}_{2}}<100 \mathrm{~mm} \mathrm{Hg}\right){ }^{31}$
In our survey, almost three quarters of the intensivists who use NMB in treating patietns with moderate to severe ARDS usually administer NMB for 25-48 h, and another $14.1 \%$ usually administer NMB for $>48 \mathrm{~h}$. These results are in agreement with other recent surveys. Duan et $\mathrm{al}^{30}$ found that subjects with ARDS treated with NMB received the agents for a median of 3 days. Alhurani et al ${ }^{32}$ found that half of the intensivists surveyed about treating refractory hypoxemia administer NMB for 24-48 $\mathrm{h}$ and $19.7 \%$ administer NMB for $>48 \mathrm{~h}$.

Because the results of the ROSE trial, ${ }^{26}$ which sought to confirm the results of the ACURASYS trial, ${ }^{13}$ were expected to be published during our planned trial of therapeutic hypothermia in ARDS, we sought to understand the relative importance of the original ACURASYS trial ${ }^{13}$ results in the decision to initiate NMB treatment in ARDS patients. We included 4 identically-worded questions asking the respondents to grade the importance they placed on each of 4 potential justifications for starting NMB in patients with moderate to severe ARDS. Based on a mean weighted score, the most important indication for initiating NMB in patients with moderate to severe ARDS was to allow compliance with ARDSNet mechanical ventilation guidelines, followed by promoting synchrony with mechanical ventilation; the results of the ACURASYS trial ranked third, and facilitating prone positioning fourth of the 4 possible justifications. A subgroup analysis showed no difference in the distribution of answers about NMB justifications across subgroups based on years of critical care experience, the number of patients with moderate to severe ARDS cared for per year, or the type of institution or ICU in which they practiced. The importance placed on facilitating mechanical ventilation is consistent with the established effectiveness of NMB agents as ancillary therapy to facilitate effective mechanical ventilation in $\operatorname{ARDS}^{19}$ and the 


\section{NMB Use In Patients With ARDS}

adoption of ARDSNet mechanical ventilator guidelines. ${ }^{12}$ However, to our knowledge, this is the first survey to address the relative importance of physiological and clinical considerations and the ACURASYS trial ${ }^{13}$ results in the decision to initiate NMB use in ARDS. Furthermore, the low proportion of respondents who used a fixed NMB-dosing strategy, as was used in the ACURASYS trial and the ROSE trial, ${ }^{26}$ is consistent with the lesser importance placed on the ACURASYS trial results than on the effectiveness of these agents in facilitating mechanical ventilation.

There are several, largely unavoidable limitations of this study. Our analysis is based on responses to a survey rather than on prospective observation. Because the survey is heavily weighted toward internists practicing critical care medicine in combination with pulmonary medicine in academic medical ICUs, the results may not be generalizable to all other types of intensivist practice. The response rate of $27.2 \%$ of delivered email invitations is low by historical standards, ${ }^{33}$ but it is within the range of response rates for external, online physician surveys. ${ }^{34-36}$ We estimated potential nonresponder bias based on the continuum of resistance model described by Lin and Schaeffer ${ }^{28}$ and found no difference in the pattern of survey responses between early and late responders. The results of this analysis reduces but does not eliminate the possibility of significant nonresponder bias.

Nevertheless, we believe that the results of this survey show that intensivists frequently use NMB to manage patients with moderate to severe ARDS and do so predominantly to optimize mechanical ventilation. The lesser importance placed on the ACURASYS trial results in deciding to initiate NMB in patients with ARDS supported the feasibility of our planned study of therapeutic hypothermia in patients with ARDS who were receiving NMB as part of their clinical management irregardless of the results of the ROSE trial. Since completion of this paper, the results of the ROSE trial have been published ${ }^{37}$ and showed neither harm nor benefit of NMB for $48 \mathrm{~h}$ in patients with moderate to severe ARDS.

\section{Conclusions}

We conclude that NMB is frequently used by academic intensivists in patients with moderate to severe ARDS. The most important consideration in deciding to use NMB in such patients is to facilitate lung-protective mechanical ventilation and prevent patient-ventilator asynchrony. Most intensivists adjust the dose of NMB agent based on monitoring response to neural stimulation or achieving ventilator synchrony.

\section{REFERENCES}

1. Li G, Malinchoc M, Cartin-Ceba R, Venkata CV, Kor DJ, Peters SG, et al. Eight-year trend of acute respiratory distress syndrome: a pop- ulation-based study in Olmsted County, Minnesota. Am J Respir Crit Care Med 2011;183(1):59-66.

2. Rubenfeld GD, Caldwell E, Peabody E, Weaver J, Martin DP, Neff $\mathrm{M}$, et al. Incidence and outcomes of acute lung injury. N Engl J Med 2005;353(16):1685-1693.

3. Herridge MS, Cheung AM, Tansey CM, Matte-Martyn A, DiazGranados N, Al-Saidi F, et al. One-year outcomes in survivors of the acute respiratory distress syndrome. New Engl J Med 2003;348(8): 683-693.

4. Herridge MS, Tansey CM, Matte A, Tomlinson G, Diaz-Granados $\mathrm{N}$, Cooper A, et al. Functional disability 5 years after acute respiratory distress syndrome. New Engl J Med 2011;364(14):1293-1304.

5. McHugh LG, Milberg JA, Whitcomb ME, Schoene RB, Maunder RJ, Hudson LD. Recovery of function in survivors of the acute respiratory distress syndrome. Am J Respir Crit Care Med 1994; 150(1):90-94

6. Fan E, Dowdy DW, Colantuoni E, Mendez-Tellez PA, Sevransky JE, Shanholtz C, et al. Physical complications in acute lung injury survivors: a two-year longitudinal prospective study. Crit Care Med 2014;42(4):849-859.

7. Needham DM, Wozniak AW, Hough CL, Morris PE, Dinglas VD, Jackson JC, et al. Risk factors for physical impairment after acute lung injury in a national, multicenter study. Am J Respir Crit Care Med 2014;189(10):1214-1224.

8. Bienvenu OJ, Colantuoni E, Mendez-Tellez PA, Dinglas VD, Shanholtz C, Husain N, et al. Depressive symptoms and impaired physical function after acute lung injury: a 2-year longitudinal study. Am J Respir Crit Care Med 2012;185(5):517-524.

9. Bienvenu OJ, Gellar J, Althouse BM, Colantuoni E, Sricharoenchai T, Mendez-Tellez PA, et al. Post-traumatic stress disorder symptoms after acute lung injury: a 2-year prospective longitudinal study. Psychol Med 2013;43(12):2657-2671.

10. Ware LB, Matthay MA. The acute respiratory distress syndrome. N Engl J Med 2000;342(18):1334-1349.

11. Slutsky AS, Tremblay LN. Multiple system organ failure: is mechanical ventilation a contributing factor? Am J Respir Crit Care Med 157(6 Pt 1):1721-1725, 1998.

12. The Acute Respiratory Distress Syndrome Network. Ventilation with lower tidal volumes as compared with traditional tidal volumes for acute lung injury and the acute respiratory distress syndrome. N Engl J Med 2000;342(18):1301-1308.

13. Papazian L, Forel JM, Gacouin A, Penot-Ragon C, Perrin G, Loundou A, et al; ACURASYS Study Investigators. Neuromuscular blockers in early acute respiratory distress syndrome. N Engl J Med 2010; 363(12):1107-1116.

14. Guerin C, Reignier J, Richard JC, Beuret P, Gacouin A, Boulain T, et al. Prone positioning in severe acute respiratory distress syndrome. New Engl J Med 2013;368(23):2159-2168.

15. Phua J, Badia JR, Adhikari NK, Friedrich JO, Fowler RA, Singh JM, et al. Has mortality from acute respiratory distress syndrome decreased over time? A systematic review. Am J Respir Crit Care Med 2009;179(3):220-227.

16. Villar J, Blanco J, Kacmarek RM. Current incidence and outcome of the acute respiratory distress syndrome. Curr Opin Crit Care 2016; 22(1):1-6.

17. Shah NG, Cowan MJ, Pickering E, Sareh H, Afshar M, Fox D, et al. Nonpharmacologic approach to minimizing shivering during surface cooling: a proof of principle study. J Crit Care 2012;27(6):746 e741748.

18. Slack DF, Corwin DS, Shah NG, Shanholtz CB, Verceles AC, Netzer G, et al. Pilot feasibility study of therapeutic hypothermia for moderate to severe acute respiratory distress syndrome. Crit Care Med 2017;45:1152-1157. 


\section{NMB Use In Patients With ARDS}

19. Light RW, Bengfort JL, George RB. The adult respiratory distress syndrome and pancuronium bromide. Anesth Analg 1975;54(2):219223.

20. Hansen-Flaschen JH, Brazinsky S, Basile C, Lanken PN. Use of sedating drugs and neuromuscular blocking agents in patients requiring mechanical ventilation for respiratory failure: a national survey. JAMA 1991;266(20):2870-2875.

21. Brower RG, Lanken PN, MacIntyre N, Matthay MA, Morris A, Ancukiewicz M, et al. Higher versus lower positive end-expiratory pressures in patients with the acute respiratory distress syndrome. N Engl J Med 2004;351(4):327-336.

22. Meade MO, Cook DJ, Guyatt GH, Slutsky AS, Arabi YM, Cooper DJ, et al. Ventilation strategy using low tidal volumes, recruitment maneuvers, and high positive end-expiratory pressure for acute lung injury and acute respiratory distress syndrome: a randomized controlled trial. JAMA 2008;299(6):637-645.

23. Mercat A, Richard JC, Vielle B, Jaber S, Osman D, Diehl JL, et al. Positive end-expiratory pressure setting in adults with acute lung injury and acute respiratory distress syndrome: a randomized controlled trial. JAMA 2008;299(6):646-655.

24. Talmor D, Sarge T, Malhotra A, O'Donnell CR, Ritz R, Lisbon A, et al. Mechanical ventilation guided by esophageal pressure in acute lung injury. N Engl J Med 2008;359(20):2095-2104.

25. Sessler CN. Counterpoint: should paralytic agents be routinely used in severe ARDS? No. Chest 2013;144(5):1442-1445.

26. Huang DT, Angus DC, Moss M, Thompson BT, Ferguson ND, Ginde A, et al. Design and rationale of the reevaluation of systemic early neuromuscular blockade trial for acute respiratory distress syndrome. Ann Am Thorac Soc 2017;14(1):124-133.

27. Eysenbach G. Improving the quality of web surveys: the Checklist for Reporting Results of Internet E-Surveys (CHERRIES). J Med Internet Res 2004;6(3):e34.

28. Lin IF, Schaeffer NC. Using survey participants to estimate the impact of nonparticipation. Public Opin Q 1995;59:236-258.
29. Bellani G, Laffey JG, Pham T, Fan E, LUNG SAFE Investigators and the ESICM Trials Group. The LUNG SAFE study: a presentation of the prevalence of ARDS according to the Berlin Definition! Crit Care 2016;20:268.

30. Duan EH, Adhikari NKJ, D'Aragon F, Cook DJ, Mehta S, Alhazzani $\mathrm{W}$, et al. Management of acute respiratory distress syndrome and refractory hypoxemia: a multicenter observational study. Ann Am Thorac Soc 2017;14(12):1818-1826.

31. Torbic H, Bauer SR, Personett HA, Dzierba AL, Stollings JL, Ryder LP, et al. Perceived safety and efficacy of neuromuscular blockers for acute respiratory distress syndrome among medical intensive care unit practitioners: a multicenter survey. J Crit Care 2017;38:278-283.

32. Alhurani RE, Oeckler RA, Franco PM, Jenkins SM, Gajic O, Pannu SR. Refractory hypoxemia and use of rescue strategies: a U.S. national survey of adult intensivists. Ann Am Thorac Soc 2016;13(7): 1105-1114.

33. Baruch Y, Holtom B. Survey response rate levels and trends in organizational research. Hum Rel 2008;61(8):1139-1160.

34. Aitken C, Power R, Dwyer R. A very low response rate in an on-line survey of medical practitioners. Aust NZ J Public Health 2008; 32(3):288-289

35. Cook DA, Wittich CM, Daniels WL, West CP, Harris AM, Beebe TJ. Incentive and reminder strategies to improve response rate for internet-based physician surveys: a randomized experiment. J Med Internet Res 2016;18(9):e244.

36. Cunningham CT, Quan H, Hemmelgarn B, Noseworthy T, Beck CA, Dixon E, et al. Exploring physician specialist response rates to webbased surveys. BMC Med Res Methodol 2015;15:32.

37. National Heart, Lung, and Blood Institute PETAL Clinical Trials Network; Moss M, Huang DT, Brower RG, Ferguson ND, Ginde AA, et al. Early Neuromuscular Blockade in the Acute Respiratory Distress Syndrome. N Engl J Med 2019;380(21):1997-2008. 